\title{
Application of Glomus deserticola as bio-fertilizer of Gasteraloe in saline growing medium and biocontrol of Fusarium $s p$.
}

\author{
Domenico Prisa * \\ CREA Research Centre for Vegetable and Ornamental Crops, Council for Agricultural Research and Economics, Via dei \\ Fiori 8, 51012 Pescia, PT, Italy.
}

Magna Scientia Advanced Biology and Pharmacy, 2021, 01(02), 001-008

Publication history: Received on 09 December 2020; revised on 16 December 2020; accepted on 18 December 2020

Article DOI: https://doi.org/10.30574/msabp.2021.1.2.0023

\begin{abstract}
In this study the possibility of using a biostimulant based on Glomus deserticola to improve the growth and quality of Gasteraloe plants and protection against Fusarium sp. was evaluated. Objectives of the work were: i) use Glomus deserticola to assess whether the use of this Arbuscular mycorrhizal fungi can increase the growth rate of Gasteraloe plants generally slow in their growth cycle; ii) consider if the use of Glomus deserticola can lead to an increase in plant resistance under saline substrate conditions; iii) evaluate how the use of Glomus deserticola allows greater protection of plants from Fusarium sp. which often affects the roots of these succulents. The four experimental groups in cultivation were: i) group without Glomus, irrigated with water and substrate previously fertilized; ii) group without Glomus, irrigated with salt water $\left(0.50 \mathrm{~g}\right.$ of $\mathrm{NaCl} \mathrm{Kg}^{-1}$ dry soil) and substrate previously fertilized; iii) group with Glomus deserticola, irrigated with water and substrate previously fertilized; iv) group with Glomus deserticola, irrigated with salt water ( $0.50 \mathrm{~g}$ of $\mathrm{NaCl} \mathrm{Kg}{ }^{-1}$ dry soil) and substrate previously fertilized. The test showed a significant increase in agronomic parameters analyzed in plants treated with Glomus deserticola on Gasteraloe cv. Magica and Gasteraloe aristata $x$ platinum. The test also highlighted how the use of mycorrhizae in particular of Glomus spp. can determine a greater resistance against salt stress and greater protection against attacks of Fusarium $s p$. The application of mycorrhizae in the cultivation of succulent plants guarantees growers the possibility of obtaining a superior quality product, greater resistance to biotic and abiotic stress, an increase in the growth rate and mineral content of the tissues, aspects that are then found in the improvement of the quality of the plants and consequently their commercialization.
\end{abstract}

Key-words: Sustainable Applications; Succulent Plants; Biofertilizers; Rhizosphere; Microorganisms

\section{Introduction}

Gasteraloe plants, also known as x Gastrolea, are a particular type of succulent plants obtained from the hybridization between Gasteria and Aloe. Native to South Africa, Gasteraloe plants have thick succulent leaves with toothed margins. Usually these plants produce tubular flowers that bloom on stems that can be up to $1 \mathrm{~m}$ long. Gasteraloe hybrids are stemless or almost stemless. Gonialoe and Aristaloe aristata are particularly used for these hybrids, as they are much more susceptible to hybridization with gasteries than most other "aloes" [1].The reproduction takes place through shoots that grow from the base of the mother plant, need light and must be protected from the afternoon sun. In Mediterranean environment Gasteraloe usually grows as perennial [2].

Arbuscular mycorrhizal fungi (AMF) are symbiotic soil fungi that can colonize the roots of most plants. The genus Glomus lives mainly in neutral and alkaline agricultural soils. The fungus-plant association usually increases water and nutrient uptake by the roots [3,4], improving the hydraulic conductivity of the roots [5] or modifying the root

\footnotetext{
${ }^{*}$ Corresponding author: Domenico Prisa

CREA Research Centre for Vegetable and Ornamental Crops, Council for Agricultural Research and Economics, Via dei Fiori 8, 51012 Pescia, PT, Italy.
}

Copyright (C) 2021 Author(s) retain the copyright of this article. This article is published under the terms of the Creative Commons Attribution Liscense 4.0. 
architecture [6]. Accordingly, the plant has a variety of benefits that can lead to increased growth, improved water relationships [7], increased nutrient uptake compared to non-mycorrhizal controls [8] and a change in root morphology [9]. The effect of AMF on the drought resistance of host plants has been studied $[10,11]$ and it has been shown that mycorrhizal infection increases the ability of plants to extract water and nutrients [12,13]. The response of mycorrhizal plants to drought stress depends on the specific fungal species [14], the interaction between the plant species and the introduced fungi and the level of drought stress. This association is interesting for those looking for drought-resistant species/plants that can be used for re-vegetation and soil conservation [15] of semi-arid areas where the availability of water for irrigation is limited. In the Mediterranean area, the limited rainfall and the high evaporative demand of the atmosphere combine with anthropogenic disturbances, making desertification a serious problem that generates a progressive reduction of plant cover coupled with rapid soil erosion [16].

AMF (Glomus deserticola) are obligate symbiotic biotrophs that increase plants' resistance to drought and pathogens, increase the contact area of plants with the soil, increase the absorption area of the roots up to 47 times, improve the absorption of water and mineral elements, increase the accidental formation of roots, promote plant growth and plant growth $[17,18,19]$. So far, literature has shown that, there is no information on the influence of G. deserticola on the growth and defense of succulent plants

In this experiment, the main objective was to:

1) Use Glomus deserticola to assess whether the use of this Arbuscular mycorrhizal fungi can increase the growth rate of Gasteraloe plants generally slow in their growth cycle;

2) Consider if the use of Glomus deserticola can lead to an increase in plant resistance under saline substrate conditions;

3) Evaluate how the use of Glomus deserticola allows greater protection of plants from Fusarium sp. which often affects the roots of these succulents.

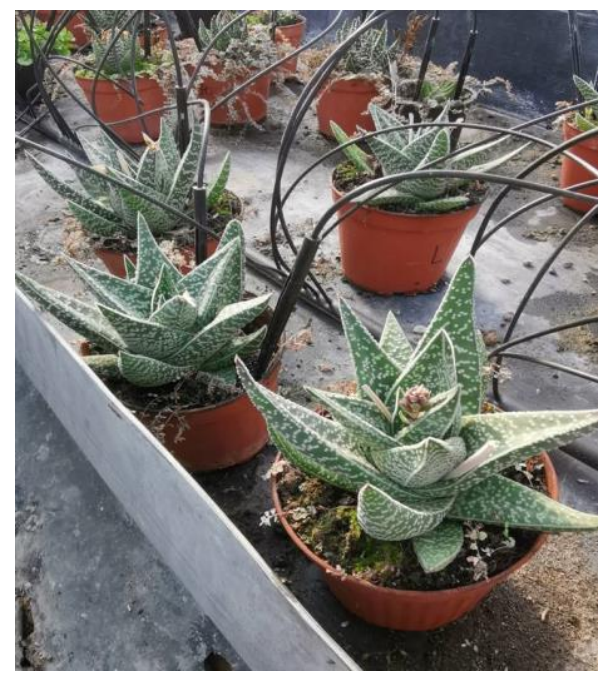

Figure 1- Details of Gasteraloe in the greenhouses of CREA-OF in Pescia

\section{Materials and methods}

\subsection{Greenhouse experiment and growing conditions}

The experiments, started in March 2020, were conducted in the greenhouses of CREA-OF in Pescia (Pt), Tuscany, Italy $\left(43^{\circ} 54^{\prime} \mathrm{N} 10^{\circ} 41^{\prime} \mathrm{E}\right)$ on Gasteraloe cv Magica and Gasteraloe aristata x platinum [Fig. 1]

The plants were placed in $\emptyset 12 \mathrm{~cm}$ pots; 60 plants per thesis, divided into 3 replicas of 20 plants each. All plants were fertilized with a controlled release fertilizer ( $2 \mathrm{~kg} \mathrm{~m}^{-3}$ Osmocote Pro®, 6 months with $190 \mathrm{~g} / \mathrm{kg} \mathrm{N}, 39 \mathrm{~g} / \mathrm{kg} \mathrm{P,} 83$ g/kg K) mixed with the growing medium before transplanting.

The four experimental groups in cultivation were: 
Group without Glomus (CTRL) (peat 50\% + pumice 30\%+sand 10\%+zeolite 10\%), irrigated with water and substrate previously fertilized;

Group withouth Glomus (CTRLS) (peat 50\% + pumice 30\%+sand 10\%+zeolite 10\%), irrigated with salt water (0.50 g of $\mathrm{NaCl} \mathrm{Kg}-1$ dry soil) and substrate previously fertilized;

Group with Glomus deserticola (GD) (peat 50\% + pumice 30\% + sand 10\%+zeolite 10\%), irrigated with water and substrate previously fertilized. Gloumus deserticola has been isolated by TNC Mycorr MAX (1.2 x10 $\mathrm{spores} / \mathrm{Kg})$. Dosage: $50 \mathrm{~g}$ into 15 litres of substrate;

Group with Glomus deserticola (GDS) (peat 50\% + pumice 30\% + sand 10\%+zeolite 10\%), irrigated with salt water $(0.50$ $\mathrm{g}$ of $\mathrm{NaCl} \mathrm{Kg-1}$ dry soil) and substrate previously fertilized.

The plants were watered 2 times per week and grown for 8 months. The plants were irrigated with drip irrigation. The irrigation was activated by a timer whose program was adjusted weekly according to climatic conditions and the fraction of leaching. On October 15, 2020, plants height, leaves number, vegetative and radical weight, number and weight of new shoots, inflorescences number, inflorencences height were recorded. Additionally, in the experiment the presence of plant mortality following attacks of Fusarium sp. and N, P, K analysis (Kjeldal UDK 169; Jenway 6305016300 visible spectrophotometer) were recorded.

\subsection{Statistics}

The experiment was carried out in a randomized complete block design. Collected data were analysed by one-way ANOVA, using GLM univariate procedure, to assess significant $(P \leq 0.05,0.01$ and 0.001$)$ differences among treatments. Mean values were then separated by LSD multiple-range test $(P=0.05)$. Statistics and graphics were supported by the programs Costat (version 6.451) and Excel (Office 2010).

\section{Results}

\subsection{Plant growth}

The test showed a significant increase in agronomic parameters analyzed in plants treated with Glomus deserticola on Gasteraloe cv. Magica and Gasteraloe aristata x platinum. The test also highlighted how the use of mycorrhizae in particular of Glomus spp. can determine a greater resistance against salt stress and greater protection against attacks of Fusarium sp.

In fact, all plants treated with Glomus deserticola (GD) showed a significant increase in height and number of leaves per plant, vegetative and root weight of the plants, number and weight of new shoots and inflorescences. There was also an increase in nitrogen, phosphorus and potassium content in plant tissue of plants grown in substrates inoculated with mycorrhizae. The use of mycorrhizae has effectively demonstrated that the use of certain microorganisms has a beneficial effect against pathogenic fungi in particular Fusarium sp.

In particular on Gasteraloe cv. Magica (Table 1), the treatment with Glomus deserticola (GD) significantly improved the plant height with $13.48 \mathrm{~cm}$, compared to $12.46 \mathrm{~cm}$ (CTRL), $12.26 \mathrm{~cm}$ (GDS) and $11.38 \mathrm{~cm}$ (CTRLS). The use of mycorrhizae significantly increased the number of leaves per plant by 8.42 (GD) compared to 6.41 (CTRL) of untreated control, 5.23 (GDS) and 4.79 (CTRLS). It also improved vegetative weight, $39.38 \mathrm{~g}$ (GD), 34.71 (CTRL), 34.52 (GDS) and 33.48 (CTRLS) and root weight $26.56 \mathrm{~g}$ (CTRL), $25.11 \mathrm{~g}$ (CTRL), $24.34 \mathrm{~g}$ (GDS) and $23.02 \mathrm{~g}$ (CTRLS) [Fig. 2,4b].

The test also showed a significant increase in the number of new shoots 1.81 (GD) compared to 1.23 (GDS), 1.04 (CTRL) and 0.45 (CTRLS) and the shoots weight $5.12 \mathrm{~g}$ (GD), $4.11 \mathrm{~g}$ (CTRL), $3.48 \mathrm{~g}$ (GDS) and $2.66 \mathrm{~g}$ (CTRLS). There was also an improvement in the inflorescences number in (GD) with 1.64 compared to 1.00 (GDS), 0.64 (CTRL) and 0.00 (CTRLS) and the weight of inflorescences $2.86 \mathrm{~g}$ (GD), $1.94 \mathrm{~g}$ (GDS), $1.36 \mathrm{~g}$ (CTRL) and 0.00 (CTRLS).

Similarly in Gasteraloe aristata x platinum (Table 2), treatment with Glomus deserticola (GD) showed a significant increase in plant height of $5.26 \mathrm{~cm}$, compared to $4.52 \mathrm{~cm}$ CTRL), $4.12 \mathrm{~cm}$ (GDS) and $3.51 \mathrm{~cm}$ (CTRLS). There was also a considerable improvement in the number of leaves in (GD) with 7.81 compared to 6.43 (CTRL), 5.44 (GDS) and 5.21 (CTRLS). Even in this case it was found that the use of Gasteraloe deserticola determined a significant increased in vegetative weight $38.22 \mathrm{~g}$ (GD), $35.84 \mathrm{~g}$ (CTRL), $35.55 \mathrm{~g}$ (GDS) and $32.93 \mathrm{~g}$ (CTRLS) and radical weight $30.68 \mathrm{~g}$ (GD), $24.26 \mathrm{~g}$ (CTRL), $23.91 \mathrm{~g}$ (GDS) and $22.42 \mathrm{~g}$ (CTRLS) [Fig 3,4a]. The test also showed a significant increase in the number of new shoots 0.61 (GD) compared to 0.23 (GDS), no inflorescences were produced in (CTRL) and (CTRLS) shoot weight $1.34 \mathrm{~g}(\mathrm{GD})$ and $0.42 \mathrm{~g}(\mathrm{GDS})$. 
The treatment with Glomus deserticola had also resulted in a significant increase in nitrogen, phosphorus and potassium content in the plant tissues of the treated plants. In both types of Gasteraloe in cultivation, the thesis with (GD) was the best compared to the others, highlighting how the use of mycorrhizae can improve the absorption of minerals from the soil even under conditions of saline stress. It was also noted that the thesis treated with Glomus deserticola there was a significant reduction in the presence of Fusarium sp. effect probably due to the biocontrol action determined by the presence of mycorrhizae in the substrate.

Table 1 - Evaluation of Glomus deserticola on agronomic characters on plants of Gasteraloe cv Magica

\begin{tabular}{|c|c|c|c|c|c|c|c|c|}
\hline Groups & $\begin{array}{c}\text { PH } \\
(\mathrm{cm})\end{array}$ & $\begin{array}{c}\text { LN } \\
\left(n^{\circ}\right)\end{array}$ & $\begin{array}{l}\text { VW } \\
\text { (g) }\end{array}$ & $\begin{array}{r}\text { RW } \\
\text { (g) }\end{array}$ & $\begin{array}{l}\text { NSN } \\
\left(n^{\circ}\right)\end{array}$ & $\begin{array}{c}\text { NSW } \\
\text { (g) }\end{array}$ & $\begin{array}{c}\text { IN } \\
\left(n^{\circ}\right)\end{array}$ & $\begin{array}{l}\text { IW } \\
\text { (g) }\end{array}$ \\
\hline CTRL & $12,46^{b}$ & $6,41^{b}$ & $34,71^{b}$ & $25,11^{b}$ & $1,04^{b}$ & $4,11^{b}$ & $0,64 \mathrm{~b}$ & $1,36^{b}$ \\
\hline CTRLS & $11,38^{c}$ & $4,79^{c}$ & $33,48^{c}$ & $23,02 \mathrm{~d}$ & $0,45^{c}$ & $2,66^{d}$ & $0,00^{c}$ & $0,00^{c}$ \\
\hline GD & 13,48 a $^{-}$ & $8,42^{\mathrm{a}}$ & 39,38 a & $26,56^{\mathrm{a}}$ & $1,81^{\mathrm{a}}$ & $5,12^{\mathrm{a}}$ & $1,64^{\mathrm{a}}$ & $2,86^{a}$ \\
\hline GDS & $12,26^{b}$ & $5,23^{c}$ & 34,52 b & $24,34^{c}$ & $1,23 \mathrm{~b}$ & $3,48^{c}$ & $1,00^{b}$ & $1,94 \mathrm{~b}$ \\
\hline ANOVA & $* * *$ & $* * *$ & *** & $* * *$ & $* * *$ & *** & $* * *$ & $* * *$ \\
\hline
\end{tabular}

One-way ANOVA; n.s. - non significant; ${ }^{* * * * * * *}$ - significant at $\mathrm{P} \leq 0.05,0.01$ and 0.001 , respectively; different letters for the same element indicate significant differences according to Tukey's (HSD) multiple-range test ( $\mathrm{P}=0.05)$. Legend: (CTRL) control; (CTRLS) control+salt water; (GD) Glomus deserticola; (GDS) Glomus deserticola+salt water; PH: plant height; LN: leaves number; VW: vegetative weight; RW: roots weight; NSN: new shoot number; NSW: new shoot weight; IN: inflorescences number; IW: inflorescences weight

Table 2 - Evaluation of Glomus deserticola on agronomic characters on plants of Gasteraloe aristata x platinum

\begin{tabular}{|c|c|c|c|c|c|c|c|c|}
\hline Groups & $\begin{array}{c}\text { PH } \\
(\mathrm{cm})\end{array}$ & $\begin{array}{c}\text { LN } \\
\left(n^{\circ}\right)\end{array}$ & $\begin{array}{l}\text { VW } \\
\text { (g) }\end{array}$ & $\begin{array}{c}\text { RW } \\
\text { (g) }\end{array}$ & $\begin{array}{l}\text { NSN } \\
\left(n^{\circ}\right)\end{array}$ & $\begin{array}{c}\text { NSW } \\
\text { (g) }\end{array}$ & $\begin{array}{c}\text { IN } \\
\left(n^{\circ}\right)\end{array}$ & $\begin{array}{l}\text { IW } \\
\text { (g) }\end{array}$ \\
\hline CTRL & $4,52^{b}$ & $6,43^{b}$ & $35,84^{b}$ & $24,26^{b}$ & $1,81^{b}$ & $5,36^{b}$ & $0,00^{b}$ & $0,00^{b}$ \\
\hline CTRLS & $3,51^{d}$ & $5,21^{c}$ & $32,93^{c}$ & $22,42^{c}$ & $1,22^{b}$ & $4,56^{c}$ & $0,00^{b}$ & $0,00^{b}$ \\
\hline GD & $5,26^{\mathrm{a}}$ & $7,81^{\mathrm{a}}$ & $38,22^{\text {a }}$ & 30,68 a & $3,42^{\text {a }}$ & $6,21^{a}$ & $0,61^{\mathrm{a}}$ & $1,34^{\mathrm{a}}$ \\
\hline GDS & $4,12^{c}$ & $5,44^{c}$ & $35,55^{b}$ & $23,91^{b}$ & $1,43^{b}$ & $5,04 \mathrm{~b}$ & 0,23 ab & $0,42^{a b}$ \\
\hline ANOVA & $* * *$ & $* * *$ & $* * *$ & $* * *$ & $* * *$ & $* * *$ & ns & $*$ \\
\hline
\end{tabular}

One-way ANOVA; n.s. - non significant; ${ }^{*}, * * * * *$ - significant at $\mathrm{P} \leq 0.05,0.01$ and 0.001 , respectively; different letters for the same element indicate significant differences according to Tukey's (HSD) multiple-range test ( $\mathrm{P}=0.05)$. Legend: (CTRL) control; (CTRLS) control + salt water; (GD) Glomus deserticola; (GDS) Glomus deserticola + salt water; PH: plant height; LN: leaves number; VW: vegetative weight; RW: roots weight; NSN: new shoot number; NSW: new shoot weight; IN: inflorescences number; IW: inflorescences weight.

Table 3 - Evaluation of the effect of Glomus deserticola on the mineral absorption and protection against Fusarium sp. in Gasteraloe plants

\begin{tabular}{|c|c|c|c|c|c|c|c|c|}
\hline \multirow[t]{2}{*}{ Groups } & & \multicolumn{3}{|c|}{ Gasteraloe cv Magica } & & \multicolumn{3}{|c|}{ Gasteraloe platinum $\mathrm{x}$ aristata } \\
\hline & $\begin{array}{c}N \\
(g / K g)\end{array}$ & $\begin{array}{c}P \\
(g / K g)\end{array}$ & $\begin{array}{c}\mathrm{K} \\
\text { (g/kg) }\end{array}$ & $\begin{array}{l}\text { Fusarium } \\
\text { sp. plants } \\
\text { affected } \\
\left(\mathrm{n}^{\circ}\right)\end{array}$ & $\begin{array}{c}N \\
(g / K g)\end{array}$ & $\begin{array}{c}P \\
(g / K g)\end{array}$ & $\begin{array}{c}\mathrm{K} \\
(\mathrm{g} / \mathrm{kg})\end{array}$ & $\begin{array}{c}\text { Fusarium } \\
\text { sp. plants } \\
\text { affected } \\
\left(n^{\circ}\right)\end{array}$ \\
\hline CTRL & 8,14 b & $1,18^{c}$ & $12,50 \mathrm{~b}$ & 1,41 a & $5,63 \mathrm{~b}$ & $2,43 \mathrm{~b}$ & 7,14 b & 1,20 a \\
\hline CTRLS & $6,90^{c}$ & $0,94 \mathrm{~d}$ & $10,40^{c}$ & 1,43 a & $5,15^{c}$ & $2,19^{c}$ & $6,31^{c}$ & 1,00 a \\
\hline GD & 9,69 a & 2,67 a & 13,58 a & $0,64 \mathrm{~b}$ & 6,49 a & 3,78 a & 7,99 a & $0,00 \mathrm{~b}$ \\
\hline GDS & 8,15 b & $2,03 \mathrm{~b}$ & $12,42^{b}$ & $0,21^{b}$ & $5,60^{b}$ & $2,39 \mathrm{~b}$ & $6,76^{b}$ & $0,23 \mathrm{~b}$ \\
\hline ANOVA & $* * *$ & $* * *$ & $* * *$ & $* *$ & $* * *$ & $* * *$ & $* * *$ & $* * *$ \\
\hline
\end{tabular}

One-way ANOVA; n.s. - non significant; ${ }^{*}, * * * * *$ - significant at $\mathrm{P} \leq 0.05,0.01$ and 0.001 , respectively; different letters for the same element indicate significant differences according to Tukey's (HSD) multiple-range test (P = 0.05). Legend: (CTRL) control; (CTRLS) control + salt water; (GD) Glomus deserticola; (GDS) Glomus deserticola + salt water; (N) nitrogen; (P) phosphorus; (K) potassium 

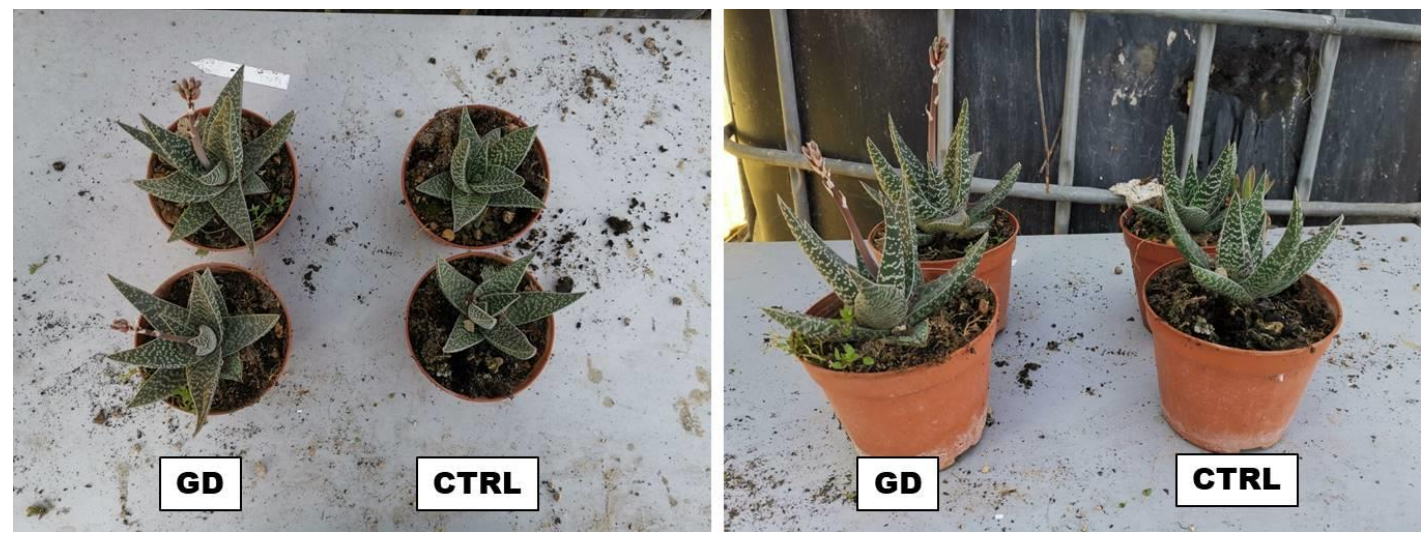

Figure 2 - Effect of Glomus deserticola on vegetative biomass and inflorescence production of Gasteraloe cv Magica Legend: (CTRL) control; (GD) Glomus deserticola
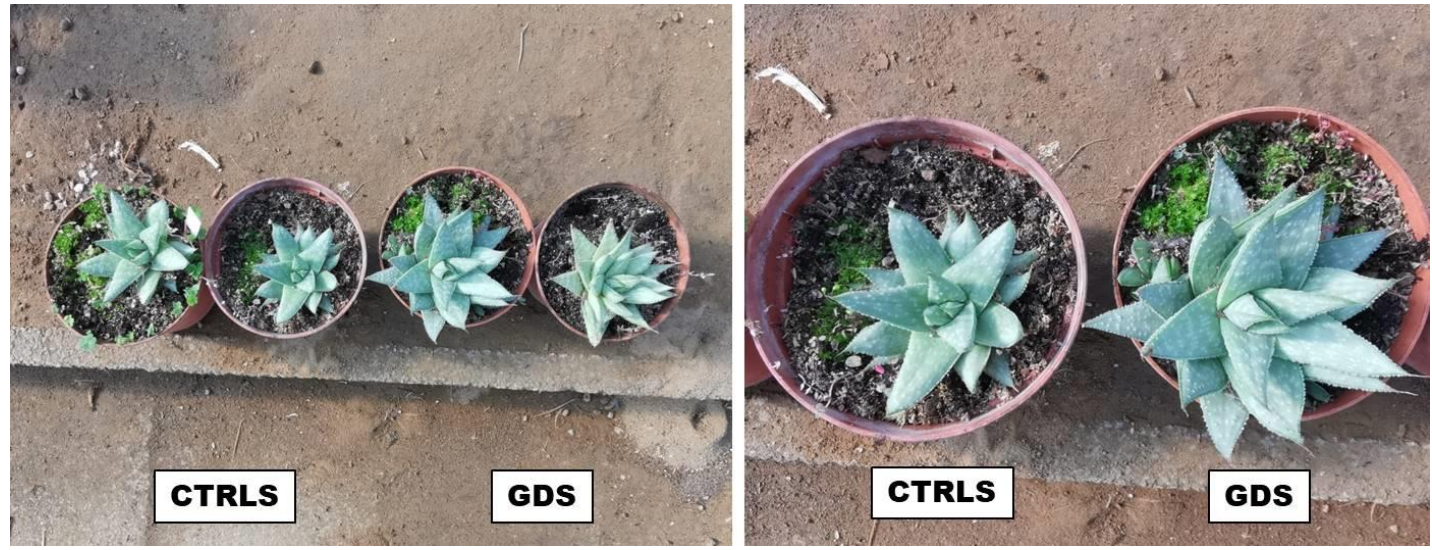

Figure 3 - Effect of Glomus deserticola on vegetative biomass of Gasteraloe platinum x aristata Legend: (CTRLS) control with salt water; (GDS) Glomus deserticola with salt water
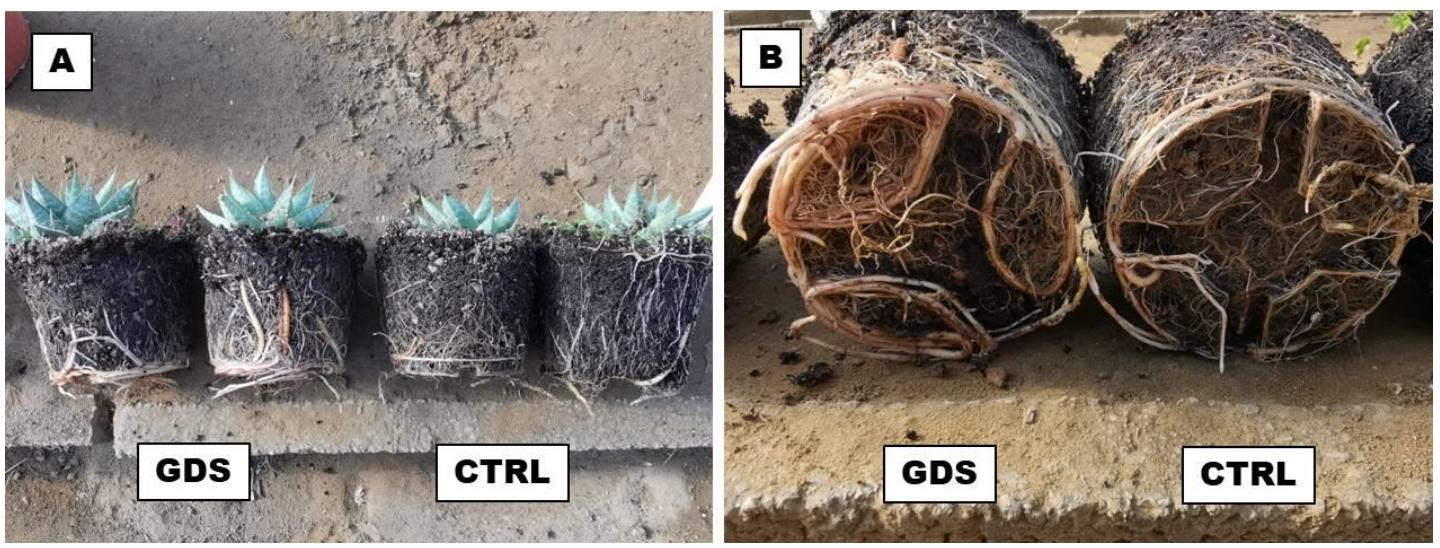

Figure 4 - Effect of Glomus deserticola on roots biomass in saline substrate of Gasteraloe platinum x aristata (A) and Gasteraloe cv Magica (B). Legend: (CTRL) control; (GDS) Glomus deserticola with salt water

\section{Discussion}

A wide range of relationships can be established between plant roots and fungi. In these relationships the plant does not show pathological symptoms due to the presence of fungal organisms. The classification of mycorrhizae is based both on morphological aspects and on where the fungus is located. Mycorrhiza is mainly established on the lateral roots and branches. Mycorrhizate roots remain shorter and tend to have a larger diameter. The external appearance varies depending on the type of fungus, the intensity of the infection and the way the root system of the plant grows [20]. 
The intensity of mycorrhizal infection varies from soil to soil. The amount of roots is higher in acid humus mor soils than in mull soils. The formation of mycorrhizal roots is favoured by conditions of nutrient deficiency, especially nitrogen, as well as intense photosynthetic activity. It seems therefore that the carbohydrate content of the roots is a factor of decisive importance and that any condition that favors the presence of an excess of carbohydrates stimulates mycorrhizal infection [21].

Mycorrhizal roots have a higher capacity to absorb mineral elements, especially nitrogen and phosphorus, than normal roots. This capacity, useful in poor soils, is favored by a greater absorbing surface area, also because from the fungal sheath branch off mycelial filaments that penetrate the surrounding soil. In addition, it seems that the fungus carries out a very intense metabolic activity and that this activity contributes to the mobilization of nutrients [12].

In this test, plants treated with Glomus deserticola showed a significant increase in plant height and leaves number, vegetative and radical weight, number and weight of new shoots, number and weight of inflorescences. Experimentation has shown how the use of mycorrhizae can increase plants resistance to saline stress. Plants grown in substrate with Glomus deserticola and wetted with salt water have grown more than control plants irrigated with water and salt. It was also evident how the use of microorganisms in particular mycorrhizae can have a biocontrol effect against plant pathogens, in this case there was a significant control effect on the mortality caused by Fusarium sp.. In addition, the use of mycorrhizae determines a significant increase in root growth and consequently the absorption of water and mineral nutrients, a mechanism that then determines an increase in mineral content in plant tissues.

Arbuscular mycorrhizae are characterized by the formation of unique structures, shrubs and vesicles of the Glomeromycota phylum fungi. In this symbiotic association, the fungus helps the plant to capture nutrients such as phosphorus, sulfur, nitrogen and micronutrients from the soil. It is believed that the development of symbiosis with arbuscular mycorrhizae played a crucial role in the initial colonization of the soil by plants and in the evolution of vascular plants [22]. This symbiosis is a highly evolved mutualistic relationship found between fungi and plants. Arbuscular mycorrhizae are found in $80 \%$ of known vascular plant families. The enormous advances in research on mycorrhizal physiology and ecology in the last 40 years have led to a greater understanding of the multiple functions of arbuscular mycorrhizae in the ecosystem. This knowledge is applicable to human efforts in ecosystem management and restoration, and in agriculture [23].

\section{Conclusion}

The test has shown how the use of Glomus deserticola in growing media can improve the quality and growth of Gasteraloe plants. In particular by increasing the height and number of leaves, the vegetative and root weight, the number of new shoots and inflorescences. In addition, there is a higher resistance of plants to saline stress in plants treated with mycorrhizae, a higher mineral content in tissues and a higher resistance to attacks of Fusarium sp. The use of Glomus deserticola can lead to an increase in the growth rate of succulent plants such as Gasteraloe and greater protection against fungal pathogens.

The application of mycorrhizae in the cultivation of succulent plants guarantees growers the possibility of obtaining a superior quality product, greater resistance to biotic and abiotic stress, an increase in the growth rate and mineral content of the tissues, aspects that are then found in the improvement of the quality of the plants and consequently their commercialization.

\section{Compliance with ethical standards}

\section{Acknowledgments}

The article is part of the "Microsuc" project: microorganisms for the growth and protection of cacti and succulent plants.

\section{Disclosure of conflict of interest}

The author declares no conflict of interest. 


\section{References}

[1] Leonard EN Unnamed hybrids of ×Gasteraloe alliance. In: Bradleya. Band 1998; 16:115-118

[2] Urs E Sukkulenten-Lexikon. Einkeimblättrige Pflanzen (Monocotyledonen) (in German), Stuttgart: Eugen Ulmer, 2001; pp. 197-199

[3] Allen EB, Cunningham GL Effects of vesicular-arbuscular mycorrhizae on Distichlis spicata under three salinity levels. New Phytol 1983; 93:227-236

[4] Ruiz Lozano JM, Symbiotic efficiency and infectivity of an autochthonous arbuscular mycorrhizal Glomus sp. from saline soils and Glomus deserticola under salinity. Mycorrhiza 2000; 10(3):137-143

[5] Safir GR, Boyer JS, Geerdemann JW Mycorrhizal enhancement of water transport in soybean. Science 1971; 148:339-346

[6] Kothari SK, Marschener H, George E Effect of VA mycorrhizal fungi and rhizosphere micro-organisms on root and shoot morphology, growth and water relations of maize. New Phytol 1990; 116:303-311

[7] Davies FT, Potter JR, Linderman RG. Drought resistance of mycorrhizal pepper plants-independent of leaf phosphorus concentration, response in gas exchange and water relations. Physiol Plant 1993; 87:45-53

[8] George E, Marschner H, Jakobsen I. Role of arbuscular mycorrhizal fungi in uptake of phosphorus and nitrogen fron soil. Crit Rev Biotechnol 1995; 15:257-270

[9] Berta G, Fusconi A, Trotta A, Scannerini S. Morphogenetic modifications induced by the mycorrhizal fungus strain E3 in the root system of Allium porrum L. New Phytol 1990; 114:207-215

[10] Allen MF. Influence of vesicular-arbuscular mycorrhizae on water movement through Bouteloua gracilis (H.B.K.) Lag ex Steud. New Phytol 1982; 91:191-196

[11] Augé RM, Shekel KA, Wample RL. Greater leaf conductance of VA mycorrhizal rose plants is not related to phosphorus nutrition. New Phytol 1986; 103:107-116

[12] Prisa D. Gigaspora Margarita use to improve flower life in Notocactus and Gymnocalycium plants and roots protection against Fusarium sp. World Journal of Biology Pharmacy and Health Sciences, 2020; 04(01):051-058

[13] Faber BA, Zasiski RJ, Munns DN, Shackel K. A method for measuring hyphal nutrient and water uptake in mycorrhizal plants. Can J Bot 1991; 69:87-94

[14] Prisa D. Effect of Glomus mosseae inoculation on growth and flowering improvement of Chamaecereus sylvestrii and Mammillaria laui. World Journal of Advanced Research and Reviews, 2019; 02(03), 31-38

[15] Savé R, Estaun V, Biel C. Water relations and fungal activity of arbuscular mycorrhizal Rosmarinus officinalis L. plants submitted to a cycle of drying/rewatering. 4th European Symposium of Mycorrhizas. Granada (Spain) 1994

[16] Naveh Z 1987. Landscape ecology, management and conservation of European and Levant Mediterranean uplands. In: Tenhunen JD (ed) Plant Response to Stress. Functional Analysis in Mediterranean Ecosystems. NATO ASI Series Ecological Sciences, Vol 15, Verlag, Berlin

[17] Nadian H, Smith SE, Alston AM and Murray RS. Effects of soil compaction on plant growth, phosphorus uptake and morphological charecteristics of vesicular-arbuscular mycorrhizal colonization of Trifolium subterraneum. New Phytology 1997; 135:303-311

[18] Davies MRH, Zhao FJ and McGrath SP. Pollution induced community tolerance of soil microbes in response to a zinc gradient. Environment Toxicology Chemistry 2004; 23:2665-2672

[19] Gregory PJ. Plant roots growth, activity and interaction with soils. Blackwell, Oxford. 2006; Pg 35-36

[20] Kaya C, Ashraf M, Sonmez O, Aydemir S, Tuna AL and Cullu MA, The influence of arbuscular mycorrhizal colonisation on key growth parameters and fruit yield of pepper plants grown at high salinity. Sci Hort , 2009; 121:1-6

[21] Selvakumar G and Thamizhiniyan P. The effect of the arbuscular mycorrhizal (AM) fungus Glomus intraradices on the growth and yield of Chilli (Capsicum annuum L.) under salinity stress. World Appl Sci J, 2011; 14:12091214 
[22] Porcel R, Aroca R and Ruiz-Lozano JM. Salinity stress alleviation using arbuscular mycorrhizal fungi. A review. Agron Sustain Dev 2012; 32:181-200.

[23] Evelin H, Kapoor R and Giri B. Arbuscular mycorrhizal fungi in alleviation of salt stress: a review. Annals Bot, 2009; 104:1263-1280

\section{Author's Short Biography}

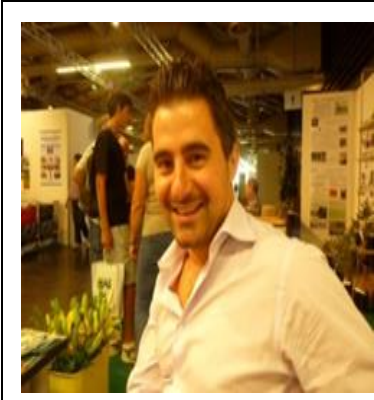

Dr. Domenico Prisa is Doctor of Philosophy - PhD, Crop Science Production (S.AnnaSchool of advances studies). Master of Science (MSc), Plant and Microbial Biotechnology (Pisa University). He is currently researcher at Council for Agricultural Research and Economics (CREA) - Landscaping Plants and Nursery Research Unit in Pescia (PT). Activities in ornamental plants and horticulture, with particular reference to the study of microorganisms and biostimulants on succulent plants and cacti. Speaker at several national and international conferences in floriculture, sustainable agriculture, innovative substrates and biostimulants, microbiology and beekeeping. His skills comprise biotechnologies and innovative crop techniques. 